\title{
THE SPATIAL VECTORCARDIOGRAM IN PROVEN ATRIAL SEPTAL DEFECT
}

\author{
BY \\ HARRY ABRAMSON AND C. R. BURTON \\ From The Department of Medicine, University of Toronto, Toronto, Canada, and The Cardiovascular Unit, Toronto \\ General Hospital, Toronto, Canada \\ Received February 10, 1961
}

The differentiation of ostium secundum from ostium primum defects of the atrial septum is now of clinical importance because the more centrally placed secundum defect may be satisfactorily closed by open heart surgery using hypothermia alone. This is considered the method of choice by some surgeons (Swan et al., 1959). The more complicated ostium primum defect with frequent involvement of the atrio-ventricular valves requires the use of a pump oxygenator for repair. Both the decision for closure of the defect and the choice of surgical technique will be influenced by the type of lesion, since the mortality is higher with surgical repair of ostium primum and atrio-ventricularis communis defects (McGoon et al., 1959). Thus, pre-operative differentiation is desirable for proper management. Spatial vectorcardiography and vectorial analysis of the scalar electrocardiogram assist in this differentiation and in some cases may be the only method of establishing the diagnosis pre-operatively.

Thirty patients with atrial septal defect have been studied recently in this laboratory. The anatomical diagnosis was subsequently confirmed in all cases; in twenty-nine by open heart surgery and in one by post mortem examination. The technique for vectorcardiography required two channels of a multi-channel photographic recorder* and we used the lead system described by Frank (1956).

The Frank system of electrode placement makes use of seven electrodes, one on the back of the neck in the midline, one on the left leg, and five on the chest. The right leg is grounded. All chest electrodes are placed at the level of the 5th interspace in the mid-sternal line, i.e. in the middle of the back (M), in the mid-sternum (E), and in the left and right mid-axillary lines (A and I respectively). A 5th electrode (C) is placed on the left præcordium so that a line joining $C$ to the centre of the thorax (O) exactly bisects the $90^{\circ}$ angle formed by lines OA and OE. The position of $\mathrm{C}$ is determined by means of a protractor, for electrode placement must be accurate if this system is to be valid.

Twenty-three patients were found to have the typical ostium secundum defect with a well defined inferior rim above the atrio-ventricular valves. In seven of these, there was also anomalous pulmonary venous drainage from the right lung. Two showed mitral stenosis and three had minimal to moderate insufficiency of the mitral valve without a cleft of either leaflet or a ventricular septal defect to suggest an A-V communis defect. A complete A-V communis defect was present in two patients and the incomplete form of ostium primum defect was present in five.

Fig. 1 to 3 show the type of vectorcardiogram and anatomical defect found in our patients. Despite the fact that several different combinations of lesions were noted at surgery or post mortem examination, only two distinctive vectorcardiographic patterns were observed in the frontal plane. In that associated with the ostium secundum defect there was clockwise rotation of the loop with most

* Electronics for Medicine Inc., White Plains, New York. 


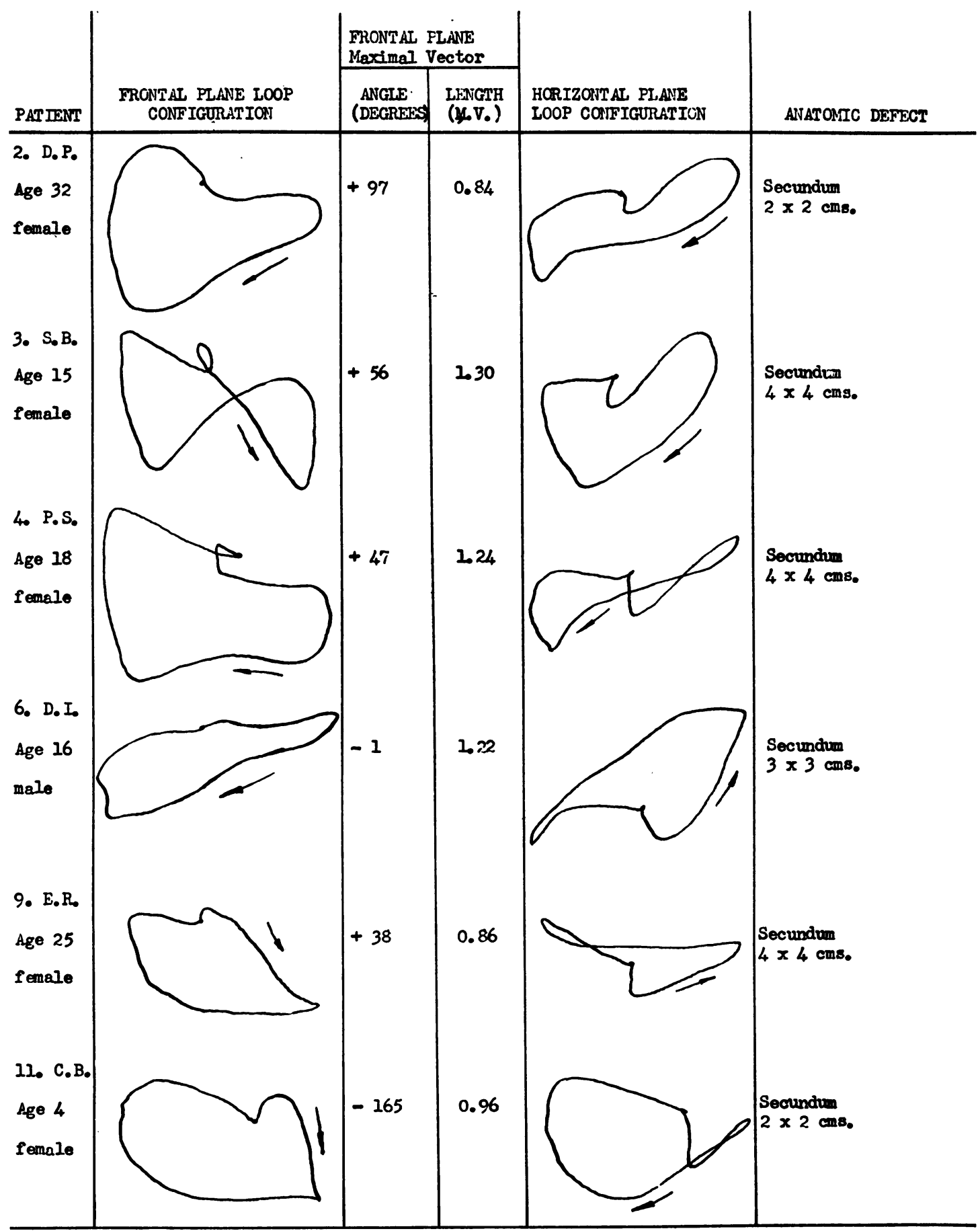

FIG. 1.-Vectorcardiogram in ostium secundum defect. 


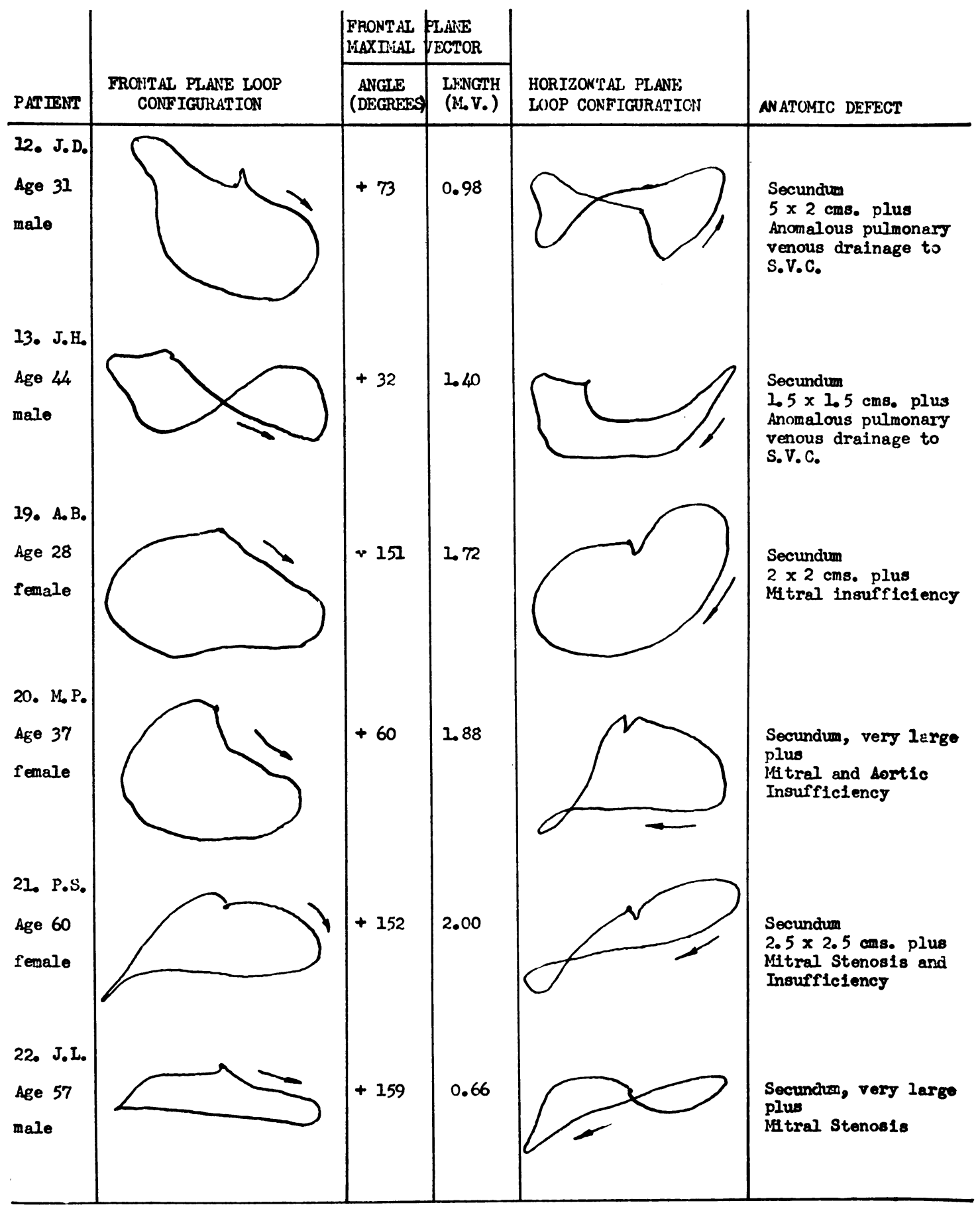

FIG. 2.-Vectorcardiogram in ostium secundum defect associated with other lesions. 


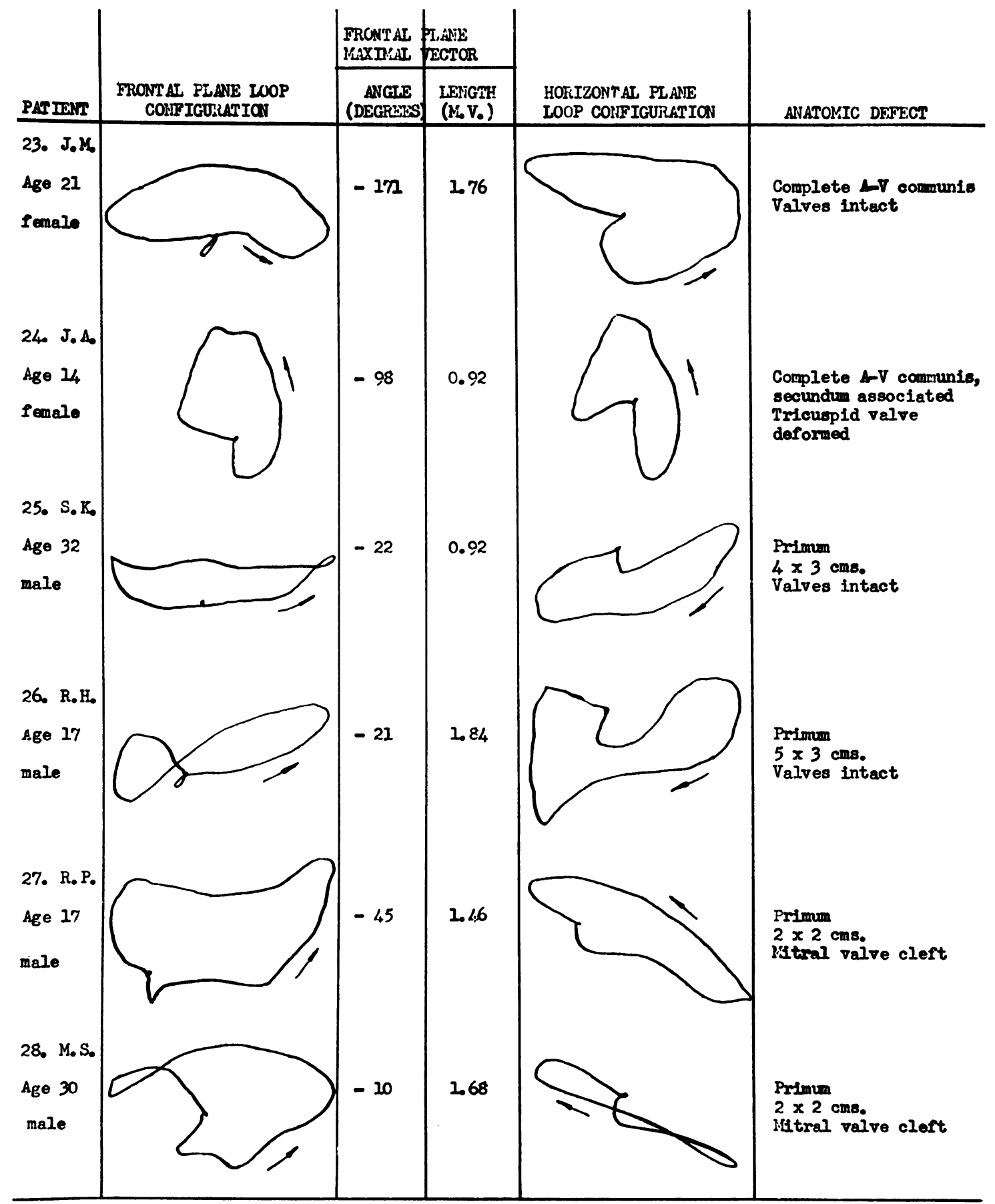

Fig. 3.-Vectorcardiogram in ostium primum and atrio-ventricularis communis defect. 
of the loop inscribed below the iso-electric point (Fig. 1-2). All twenty-three patients with secundum defects showed this, although in four there was some twisting of the mid-portion of the loop to give a figure-of-eight configuration. The angle of the maximum QRS vector ranged between $-1^{\circ}$ and $195^{\circ}$ with an average of $71^{\circ}$. Sixteen of the twenty-three showed an angle between $-1^{\circ}$ and $90^{\circ}$. The pattern seen in both ostium primum and complete $\mathrm{A}-\mathrm{V}$ communis defects was that of counter-clockwise loop inscription with most of the loop situated above the iso-electric point (Fig. 3). All seven patients with either of these two lesions showed this type of loop configuration, although in two there was twisting in the mid-portion to give a figure-of-eight pattern. The maximum QRS vector ranged between $-10^{\circ}$ and $-171^{\circ}$ with an average of $-75^{\circ}$.

Three distinctive patterns were seen in the horizontal plane projection. The loop most simulated the normal in the first type, observed in five patients (Fig. 1, No. 9). There was the usual counterclockwise inscription, but the terminal part of the loop was directed more to the right than in the normal, although it still lay in a posterior direction. The second type, present in ten patients, differed in that the terminal segment of the loop was directed to the right anteriorly (Fig. 1, No. 6). In the third type, seen in fifteen patients, the loop was inscribed in a clockwise fashion. Its initial segment was directed anteriorly and to the right; subsequently it curved to the left and then once again to the right anteriorly, then returning to the iso-electric point (Fig. 1, No. 3). Instances of terminal delay in loop inscription were observed in each pattern. The type of loop configuration as seen in the horizontal plane bore no relation to the pulmonary artery pressure determined at cardiac catheterization nor to the type of lesion observed at operation. Thus, it is evident that the ostium primum and $\mathrm{A}-\mathrm{V}$ communis defect failed to produce a pattern distinctive from that of the secundum defect in this plane. Ostium primum and secundum defects could not be differentiated on this basis.

Patients 1-18 and 30 had either uncomplicated secundum defects or secundum defects associated with anomalous pulmonary venous drainage, patients 25-26 uncomplicated primum defects. The remaining cases were examples of more complicated lesions and the anatomical defects will be described in more detail.

Case 19 (Fig. 2). Rheumatic mitral insufficiency was associated with a secundum defect. The mitral valve margin was rough and thickened, and was associated with thickened, shortened chordæ tendineæ. The aortic mitral cusp was large and mobile; the mitral valve leaflet was shallow and relatively stationary.

Case 20 (Fig. 2). There was an extremely large secundum defect completely surrounded by a muscular rim resulting in a common atrial chamber. Despite the normal appearance of the mitral valve cusps, there was slight regurgitation at the medial commissure. There was minimal aortic regurgitation.

Case 21 (Fig. 2). There was a secundum defect $2.5 \mathrm{~cm}$. in diameter with some nodular thickening of the free border of the tricuspid valve. The mitral valve was severely stenosed, thickened and firm. At autopsy it was felt that there was a slight degree of incompetence.

Case 22 (Fig. 2). There was a large secundum defect and tight mitral stenosis due to fusion of the medial commissure.

Case 23 (Fig. 3). There was an endocardial cushion defect with almost complete absence of the atrial septum. The mitral and tricuspid valve rings were completely free medially, separated by approximately $1.5 \mathrm{~cm}$. This defect was continuous with one in the membranous interventricular septum about $1 \mathrm{~cm}$. in length. There were no clefts in the mitral and tricuspid valves.

Case 24 (Fig. 3). There was an endocardial cushion defect which included atrial and ventricular septal defects as well as a deformed tricuspid valve. There was an associated patent ductus arteriosus, a separate secundum type atrial septal defect and mild pulmonary valvular stenosis.

Case 27 (Fig. 3). There was an ostium primum defect, $2 \mathrm{~cm}$. in diameter, extending to the valve cushions between the mitral and tricuspid valves. There was a cleft in the posterior leaflet of the mitral valve which allowed regurgitation of blood from the left ventricle. There was also an extremely small patent ductus arteriosus.

Case 28 (Fig. 3). There was an ostium primum defect, $2 \mathrm{~cm}$. in diameter, associated with a cleft in the mitral valve ring. There was marked mitral regurgitation and gross left atrial enlargement. The defect extended to the upper rim of the membranous interventricular septum. The tricuspid valve was competent. 


\section{DisCUSSION}

Much has been written about the electrocardiogram in atrial septal defect. References to the vectorcardiogram in this condition are less frequent, and of these, very few deal with surgically proven cases (Toscano-Barboza et al., 1956, 1958; Hamer, 1958; Burch and DePasquale, 1959; Pryor et al., 1959; Beregovich et al., 1960).

Left axis deviation in the limb leads of the standard electrocardiogram has been reported in cases of ostium primum defect. Pryor and his co-workers (1959), found true left axis deviation (more than $-30^{\circ}$ ) in 82 per cent of 33 cases, whereas none of their 100 patients with ostium secundum defect showed this. Using vectorial analysis of the standard 12 lead electrocardiogram, vector loops were constructed, which showed all 100 cases with secundum defect to have a frontal plane projection of the QRS sÊ loop below the iso-electric point and rotated in a clockwise direction. The loop in patients with ostium primum defect with left axis deviation was inscribed above the isoelectric point and in a counter-clockwise direction, although some of these showed a figure-of-eight configuration. The experience of Toscano-Barboza et al. (1958), using the standard electrocardiogram to construct vector loops, was similar. Ninety-two of 100 proven cases of secundum type defect showed frontal plane loops inscribed in a clockwise direction and lying below the iso-electric point. These same authors had been the first to describe the complete vectorcardiogram in defects involving the atrio-ventricular canal (1956). In their sixteen proven cases they found the frontal plane loop to have a counter-clockwise rotation and to be mainly superior to the iso-electric point. Some showed twisting of the mid-portion of the loop to give a narrow figure-of-eight configuration. These vectorcardiographic findings have been verified by the work of Hamer (1958), Burch and DePasquale (1959), and Beregovich et al. (1960).

The possible mechanism behind the distinctive frontal plane pattern in ostium primum and A-V communis defects is still not clearly understood. Some have suggested that mitral insufficiency might be responsible (Milnor and Bertrand, 1957). Others have postulated a specific abnormality in conduction due to the very low position of the defect in the atrial septum. Three of our patients with secundum defects had associated mitral insufficiency, but this failed to alter the frontal plane secundum pattern. The Mayo Clinic group found a similar situation in some of their secundum defects (Toscano-Barboza et al., 1958). In contrast only four of our cases of primum defect showed a mitral cleft, further evidence that mitral insufficiency by itself is not responsible for the superior position and counter-clockwise rotation of the frontal plane loop. The QRS sE loop is a manifestation of ventricular depolarization. It is difficult to conceive of an abnormality of the QRS sE loop resulting from a low-lying defect in the atrial septum. Such a defect might cause a delay in the onset of ventricular depolarization, but once this process starts, it should proceed normally. Left ventricular strain due to ventricular septal defect cannot be the cause of this loop configuration, for three of our seven cases showed no such defect. The secundum pattern was not altered by associated anomalous pulmonary venous drainage, mitral stenosis or slight aortic insufficiency. Thus it seems that the changes in the QRS sÊ loops in ostium primum defect must be due to an associated abnormality of the conducting system of the ventricles.

\section{SumMARY AND CONCLUSIONS}

The spatial vectorcardiogram (Frank lead system) has been described in twenty-three patients with ostium secundum and seven with ostium primum or A-V communis defects; the abnormalities were subsequently verified anatomically at surgery or at post mortem examination.

The frontal plane projection of the vectorcardiogram in each of these two abnormalities is quite distinctive.

Mitral insufficiency does not contribute to the primum pattern.

Spatial vectorcardiography is of decided value in the pre-operative assessment of patients with atrial septal defect. 
The authors wish to acknowledge the co-operation of the surgical staff, Doctors R. G. Bigelow, J. A. Key, and R. O. Heimbecker, and the technical assistance of Mr. Toivo Nelberg.

This work was supported by the Ontario Heart Foundation and the National Health Grants Administration, Canada.

\section{REFERENCES}

Beregovich, J., Bleifer, S., Donoso, E., and Grishman, A. (1960). Circulation, $21,63$.

Burch, G. E., and DePasquale, N. (1959). Amer. Heart J., 58319.

Frank, E. (1956). Circulation, 13, 737.

Hamer, N. A. (1958). Brit. Heart J., 20, 215.

McGoon, D. C., Dushane, J. W., and Kirklin, J. W. (1959). Surgery, 46, 185.

Milnor, W. R., and Bertrand, C. (1957). Amer. J. Med., 22, 223.

Pryor, R., Woodwark, G. M., and Blount, Jr., S. G. (1959). Amer. Heart J., 58, 689.

Swan, H., Kortz, A. B., Davies, D. H., and Blount, Jr., S. G. (1959). J. thorac. Surg., $37,521$.

Toscano-Barboza, E., Brandenburg, R. O., and Burchell, H. B. (1956). Proc. Mayo Clin., $31,513$.

,- , and Swan, H. J. C. (1958). Amer. J. of Card., 2, 698. 